\title{
FRECUENCIA DE PATÓGENOS AISLADOS EN CASOS CLÍNICOS DE DERMATITIS BACTERIANA CANINAY SU SUSCEPTIBILIDAD ANTIBIÓTICA
}

\section{Frequency of Pathogens Isolated in Clinical Cases of Canine Pioderma ANd Its ANTIMICrobial SusCeptibiLity}

\author{
Oscar Antúnez A. ${ }^{1}$, Sonia Calle E. ${ }^{1,2}$, Siever Morales C. ${ }^{1}$, Néstor Falcón P. ${ }^{3,4} \mathbf{y}$ \\ Chris Pinto J. ${ }^{1}$
}

\section{Resumen}

\begin{abstract}
La dermatitis bacteriana canina, comúnmente conocida como piodermia, es una de las principales enfermedades dermatológicas observadas en la clínica veterinaria. El presente estudio retrospectivo tuvo como objetivo determinar la frecuencia de los diferentes agentes bacterianos involucrados con esta enfermedad y los antibióticos que presentan mejor actividad inhibidora frente a los principales microorganismos patógenos. Para tal fin, se analizaron los registros de resultados de aislamiento bacteriano y antibiograma del Laboratorio de Bacteriología de la Facultad de Medicina Veterinaria de la Universidad Nacional Mayor de San Marcos, Lima, durante el periodo 2000-2006. El Staphlococcus intermedius fue la especie más aislada (70.6\%). Los antibióticos más efectivos fueron de la familia de las cefalosporinas como el ceftiofur y la cefalexina, mientras que la penicilina fue la que presentó mayor índice de resistencia.
\end{abstract}

Palabras clave: Dermatitis bacteriana canina, aislamiento bacteriano, antibiograma, Staphylococcus intermedius

\section{ABSTRACT}

The canine bacterial dermatitis, commonly known as pyoderma is one of the main skin diseases in the veterinary practice. The present retrospective study had the objective to determine the frequency of the bacteriological agents involved with the disease and the antibiotics that show better antimicrobiobial susceptibility. Laboratory records of bacterial isolation and antibiogram of the Laboratory of Bacteriology of the Veterinary Medicine Faculty, San Marcos University, Lima, were analyzed. Staphlococcus intermedius was the most commonly isolated species $(70.6 \%)$. The most effective

${ }^{1}$ Laboratorio de Microbiología y Parasitología Veterinaria, ${ }^{3}$ Laboratorio de Medicina Veterinaria Preventiva, Facultad de Medicina Veterinaria, Universidad Nacional Mayor de San Marcos, Lima

${ }^{2}$ E-mail: calleson@gmail.com

${ }^{4}$ Dirección actual: Facultad de Veterinaria y Zootecnia, Universidad Peruana Cayetano Heredia, Lima 
antibiotics were from the Cephalosporin family, especially the ceftiofur and cefalexin, and penicillin was the antibiotic with higher resistance index.

Key words: canine bacterial dermatitis, bacterial isolation, antibiogram, Staphylococcus intermedius

\section{INTRODUCCIÓN}

La piel posee una flora bacteriana que está constituida por microorganismos saprófitos cuya población permanece latente $\mathrm{y}$ en permanente mutualismo, pero además, existe otra correspondiente a microorganismos transitorios que puede llegar a la piel lesionada a partir de las mucosas superficiales del animal o desde el medio ambiente (Ihrke, 2000), generándose un desequilibrio que permite la proliferación de microorganismos oportunistas y la instalación de la infección.

La dermatitis bacteriana canina es uno de los problemas dermatológicos más comunes hallados en caninos (Swango et al., 1992; De Boer, 1997b; Ihrke, 2000; Pianta et al., 2006). La diversidad de síndromes clínicos que se observa es cuantiosa y los efectos de las lesiones varían desde un simple prurito hasta las que pueden poner en riesgo la vida del animal (Ihrke, 2000).

Un aspecto esencial en el futuro del tratamiento de las piodermias es la aparición de resistencias a diversos antibióticos, por lo que se han realizando numerosos estudios in vitro para poder establecer un perfil de sensibilidad antibacteriana ante diferentes antibióticos. Entre estos, la amoxicilina asociada con el ácido clavulánico, kanamicina, cefalexina, sulfatrimetoprim (Cavalcanti y Coutinho, 2005), fluoroquinolonas (Šeol, 2005) $\mathrm{y}$ otras (Ganière et al., 2002; Rème y Médaille, 2003; Pianta et al., 2006).

En la atención clínica veterinaria en el Perú no existe una práctica generalizada de obtener muestras para la realización de un aislamiento bacteriano y un antibiograma. Es así, que se torna empírica la elección de los antibióticos a ser empleados, con el riesgo de utilizar aquellos no indicados y favorecer el mantenimiento y la resistencia de los microorganismos patógenos con el consecuente fracaso del tratamiento. Es por este motivo que el presente estudio, en base a registros de laboratorio, busca contribuir en el conocimiento de la presentación de los agentes patógenos de la piel canina y los fármacos de mejor actividad antibiótica a ser utilizados en caso de emergencia.

\section{Materiales y Métodos}

Este estudio retrospectivo se llevó a cabo en el Laboratorio de Bacteriología de la Facultad de Medicina Veterinaria (FMV) de la Universidad Nacional Mayor de San Marcos, Lima. Se revisaron los registros de resultados de cultivo bacteriano y antibiograma $(n=620)$ provenientes de muestras de canes derivados de la Clínica de Animales Menores de la FMV y clínicas privadas de la provincia de Lima, para el diagnóstico bacteriológico durante el periodo 2000 - 2006.

Los resultados de laboratorio fueron por aislamiento bacteriano y por el test de susceptibilidad antimicrobiana. En el primer caso, las muestras (hisopados de piel de caninos con diagnóstico de dermatitis clínica) fueron sometidas al protocolo de aislamiento bacteriano del laboratorio. Este consiste básicamente en un cultivo de la muestra en caldos de enriquecimiento y posterior sembrado en agares nutritivos y medios selectivos por 24 horas a $37^{\circ} \mathrm{C}$; coloración Gram y finalmente pruebas bioquímicas (Coagulasa, ADNasa termoestable, Catalasa, Oxidasa, Citrato de Simons, TSI, Kliger, Caldo de Urea, Lisina, SIM, Gelatina, Esculina, D-Manitol, 
D-Manosa e Indol) para poder llegar al diagnóstico definitivo.

Las pruebas de sensibilidad a antibióticos se desarrollaron de acuerdo al método de Kirby Bauer (Bauer et al., 1966) determinando el halo de inhibición de las bacterias aisladas frente a los antibióticos comúnmente utilizados en la práctica clínica, de acuerdo a lo establecido por el National Committee for Clinical Laboratory Standards (NCCLS, 1997).

Los antibióticos (discos de sensibilidad) utilizados en los test de susceptibilidad se encuentran agrupados dentro de las familias de $\beta$-lactámicos (penicilina, ampicilina, amoxicilina, dicloxacilina, oxacilina, ceftiofur, cefradina, cefalotina, cefalexina), fluoroquinolonas ( enrofloxacina, norfloxacina, ciprofloxacina), lincosamidas (lincomicina, clindamicina), aminoglucósidos (amikacina, kanamicina, neomicina, gentamicina), tetraciclinas (doxiciclina, tetraciclina, oxitetraciclina), macrólidos (eritromicina), cloranfenicol, furazolidona, y antibióticos asociados (amoxicilina con ácido clavulánico, sulfatrimetoprim).

Se determinó las frecuencias de presentación de los agentes bacterianos involucrados en la casuística de la dermatitis bacteriana canina y las frecuencias de susceptibilidad a antibióticos de los principales agentes bacterianos aislados durante el periodo de estudio, identificándose los antibióticos más eficientes para este problema infeccioso.

\section{Resultados y Discusión}

El Cuadro 1 muestra la distribución de las muestras analizadas en el laboratorio por casos de dermatitis bacteriana canina que fueron derivados de diversas clínicas veterinarias. No se observa una variabilidad estacional, aunque se nota una disminución en el número de muestras en los últimos tres años, por razones ajenas al propósito de este estudio.
El cultivo bacteriológico en casos de dermatitis bacteriana canina está frecuentemente asociado a un solo microorganismo, como ha sido el caso de Staphylococcus intermedius (Ihrke, 2000). Este hecho probablemente dependa del momento y forma de tomar la muestra, ya que el $S$. intermedius actúa inicialmente sobre la lesión acondicionando un medio adecuado para la invasión secundaria de otros agentes bacterianos, generalmente gram negativos. En el presente estudio se encontró el 83.4\% (517/620) de infecciones monomicrobianas y $16.6 \%$ (103/ $620)$ de infecciones polimicrobianas.

El S. intermedius fue la especie bacteriana más aislada (Cuadro 2) con una frecuencia de 70.6\% (519/735), confirmando los resultados obtenidos por otros autores que indican frecuencias de aislamiento para esta bacteria de 72 a 92\% (Medleau et al., 1986; Noli et al., 1995; Lima et al., 2001; Cavalcanti y Coutinho, 2005). Esto, debido a que existen varios elementos claves que hacen particularmente virulentos a los estafilococos coagulasa positivos (enzimas extracelulares, toxina $\mathrm{b}$, proteína $\mathrm{A}$, toxina exfoliativa).

La presentación del Staphylococcus aureus en algunas infecciones sugiere la posibilidad de haberse adquirido de una fuente exógena humana, ya que constituye parte de la microflora de la piel y de las mucosas del hombre. La literatura menciona la posibilidad de zooantropozoonosis causadas por esos microorganismos (Simoons-Smit et al., 2000). Por otro lado, la Pseudomona aeruginosa no presentó mayor relevancia clínica, a diferencia de su comportamiento en otros casos de infecciones a la piel, como la otitis canina, probablemente porque no encuentra el microclima (ambiente húmedo) necesario para comportarse como un microorganismo altamente patógeno de la piel, como ocurre en el conducto auditivo (Swango et al., 1992). 
Cuadro 1. Distribución de la casuística de la dermatitis bacteriana canina en base a muestras cultivadas en el Laboratorio de Bacteriología de la Facultad de Medicina Veterinaria, UNMSM, durante el periodo 2000-2006

\begin{tabular}{lcccccccc}
\hline \multirow{2}{*}{ Mes } & \multicolumn{7}{c}{ Año } & Total \\
\cline { 2 - 7 } & 2000 & 2001 & 2002 & 2003 & 2004 & 2005 & 2006 & \\
\hline Enero & 5 & 16 & 31 & 9 & 3 & 7 & 6 & 77 \\
Febrero & 11 & 8 & 8 & 4 & 1 & 2 & 3 & 37 \\
Marzo & 9 & 25 & 9 & 9 & 6 & 1 & 4 & 63 \\
Abril & 11 & 12 & 18 & 13 & 3 & 1 & 4 & 62 \\
Mayo & 10 & 25 & 6 & 7 & 3 & 3 & 1 & 55 \\
Junio & 9 & 4 & 10 & 4 & 6 & 5 & 4 & 42 \\
Julio & 12 & 14 & 5 & 10 & 3 & 4 & 1 & 49 \\
Agosto & 9 & 7 & 11 & 3 & 6 & 3 & 6 & 45 \\
Setiembre & 14 & 11 & 4 & 10 & 4 & 4 & 2 & 49 \\
Octubre & 7 & 12 & 8 & 7 & 5 & 6 & 4 & 49 \\
Noviembre & 8 & 19 & 5 & 4 & 4 & 4 & 9 & 53 \\
Diciembre & 6 & 13 & 2 & 11 & 1 & 5 & 1 & 39 \\
\hline Total & 111 & 166 & 117 & 91 & 45 & 45 & 45 & 620 \\
\hline
\end{tabular}

Cuadro 2. Frecuencia de agentes bacterianos aislados de casos de dermatitis bacteriana canina en base a muestras cultivadas en el Laboratorio de Bacteriología de la Facultad de Medicina Veterinaria, UNMSM, durante el periodo 2000-2006

\begin{tabular}{lrrrrrrrrr}
\hline \multirow{2}{*}{ Agente } & \multicolumn{4}{c}{ Año } & \multicolumn{3}{c}{ Total } \\
\cline { 2 - 11 } & 2000 & 2001 & 2002 & 2003 & 2004 & 2005 & 2006 & $\mathrm{~N}^{\circ}$ & $\%$ \\
\hline Staphylococcus intermedius & 96 & 150 & 100 & 77 & 28 & 29 & 39 & 519 & 70.6 \\
Streptococcus sp. & 14 & 28 & 12 & 3 & - & - & - & 57 & 7.8 \\
Staphylococcus epidermidis & - & 1 & 3 & 11 & 16 & 8 & 3 & 42 & 5.7 \\
Enterobacterias & 11 & 12 & 2 & 7 & 4 & 4 & 2 & 42 & 5.7 \\
Bacillus sp. & 8 & 16 & 6 & 2 & - & - & - & 32 & 4.4 \\
Pseudomona aeruginosa & 3 & 10 & 7 & 1 & - & - & 6 & 27 & 3.7 \\
Staphylococcus aureus & 1 & 3 & 1 & 2 & 1 & 7 & - & 15 & 2.0 \\
Corynobacterium sp. & - & - & 1 & - & - & - & - & 1 & 0.1 \\
\hline Total & 133 & 220 & 132 & 103 & 49 & 48 & 50 & 735 & 100.0 \\
\hline
\end{tabular}


Cuadro 3. Frecuencia de susceptibilidad antibiótica (\%) del Staphylococcus intermedius en base a muestras cultivadas en el Laboratorio de Bacteriología de la Facultad de Medicina Veterinaria, UNMSM, durante el periodo 2000-2006

\begin{tabular}{lcccc}
\hline Antibiótico & $\mathrm{N}^{\mathrm{o}}$ & Sensible & Intermedio & Resistente \\
\hline Ceftiofur & 32 & 96.9 & 3.1 & - \\
Cefradina & 31 & 90.3 & - & 9.7 \\
Cefalotina & 95 & 88.4 & 1.1 & 10.5 \\
Cefalexina & 288 & 87.9 & 2.1 & 10.1 \\
Gentamicina & 315 & 87.6 & 1.9 & 10.5 \\
Norfloxacina & 42 & 85.7 & 4.8 & 9.5 \\
Ciprofloxacina & 296 & 83.1 & 4.7 & 12.2 \\
Amikacina & 41 & 82.9 & 4.9 & 12.2 \\
Amoxicilina + A. clavulánico & 256 & 82.4 & 7.8 & 9.8 \\
Enrofloxacina & 113 & 79.7 & 4.4 & 15.9 \\
Dicloxacilina & 32 & 78.1 & 6.3 & 15.6 \\
Eritromicina & 45 & 66.7 & 13.3 & 20.0 \\
Neomicina & 107 & 64.5 & 14.0 & 21.5 \\
Clindamicina & 92 & 64.1 & 10.9 & 25.0 \\
Cloranfenicol & 36 & 63.9 & 8.3 & 27.8 \\
Furazolidona & 38 & 63.2 & 10.5 & 26.3 \\
Oxacilina & 43 & 62.8 & - & 37.2 \\
Doxiciclina & 192 & 59.9 & 5.7 & 34.4 \\
Lincomicina & 127 & 59.1 & 1.6 & 39.4 \\
Amoxicilina & 243 & 54.3 & 2.9 & 42.8 \\
Kanamicina & 56 & 51.5 & 10.6 & 37.9 \\
Sulfatrimetoprim & 45.7 & 11.0 & 43.3 \\
Tetraciclina & 39.6 & 12.5 & 47.9 \\
Oxitetraciclina & 33.6 & 7.8 & 58.6 \\
Ampicilina & 31.7 & 5.0 & 63.3 \\
Penicilina & 21.5 & 2.5 & 76.0 \\
\hline
\end{tabular}

En consideración a la alta frecuencia de aislamientos de $S$. intermedius, se revisaron los resultados de la prueba de susceptibilidad antibacteriana para esta bacteria ( 425 antbiogramas), encontrándose que la penicilina fue el antibiótico que presentó mayor número de $S$. intermedius resistentes (76\%), confirmando los resultados obtenidos por
Cavalcanti y Coutinho (2005) quienes mencionan que los niveles de resistencia a ese fármaco varían de 60 a $90 \%$. Otros antibióticos que presentaron niveles altos de resistencia fueron la ampicilina (63\%), oxitetraciclina (59\%) y tetraciclina ( $48 \%$ ), que superaron sus índices de sensibilidad antimicrobiana (Cuadro 3). 
La resistencia observada en los antibacterianos $\beta$-lactámicos estaría asociada a la producción de $\beta$-lactamasas, que hidrolizan el núcleo activo de esos fármacos (Joklik et al., 1997; Malik et al., 2005), por lo que el uso de estos antibióticos resultan en medidas terapéuticas inadecuadas para el tratamiento de la dermatitis bacteriana canina (Mason, 1996; De Boer, 1997a,b; Ihrke, 2000).

La presentación de resistencia observada frente a otros antibióticos de amplio espectro podría estar asociada a la transferencia de plásmidos mediante mecanismos de intercambio de $\mathrm{ADN}$ bacteriano (transformación, conjugación y transducción). Estos pueden transferir información entre bacterias de especies distintas e incluso de géneros diferentes y los estafilococos comparten un hábitat ecológico con un amplio rango de especies gram positivas y gram negativas en la piel, superficies mucosas y tracto respiratorio de los mamíferos, por lo que están expuestos a un amplio grupo de genes de resistencia. Sin embargo, el antibiograma mostró que las cepas de $S$. intermedius fueron sensibles a la mayoría de los antibacterianos empleados, con frecuencias de sensibilidad que varían de 51.5 a 96.9\%. Los antibióticos con una alta sensibilidad ( $>80 \%$ ) fueron, en orden decreciente, ceftiofur, cefradina, cefalotina, cefalexina, gentamicina, norfloxacina, ciprofloxacina, amikacina y amoxicilina con ácido clavulánico (Cuadro 3).

La familia de antibióticos que presentó mayores índices de sensibilidad (87.9-96.9\%) fueron las cefalosporinas, conocidas además por producir resistencia en muy raras ocasiones (Kwochka, 2000). En el presente estudio, la cefalosporina que se ubicó en el primer lugar fue el ceftiofur (cefalosporina de tercera generación), antibiótico con actividad antibacteriana de amplio espectro y alta resistencia frente a cepas productoras de Blactamasas (Sumano y Ocampo, 1997), pero que tiene la desventaja de ser aplicado únicamente por vía intramuscular por lo que su uso se encuentra limitado en tratamientos a largo plazo, lo cual ocurre generalmente en casos de piodermias recurrentes. No obstante, otras cefalosporinas mostraron un buen comportamiento contra $S$. intermedius, tales como la cefalexina, cuya eficiencia en la resolución de las dermatitis bacterianas ha sido descrita previamente (Ihrke, 2000; Rème y Médaille, 2003; Lorenzana y Gómez, 2005), y que se administran por vía oral.

Los estudios de susceptibilidad antibiótica han encontrado grandes variaciones en su respuesta dependiendo de la región geográfica. Por ejemplo, la sulfatrimetoprim presentó un $45.7 \%$ de sensibilidad en el presente estudio, mientras que otros trabajos reportan entre un 80 a $100 \%$ de sensibilidad (Ganière et al., 2002; Cavalcanti y Coutinho, 2005); lo que es un claro indicativo que las poblaciones caninas han estado expuestas a diferentes niveles de un mismo tipo de antibiótico.

\section{Conclusiones}

- El Staphylococcus intermedius constituye la principal bacteria involucrada en los casos de dermatitis bacteriana canina diagnosticada en el Laboratorio de Bacteriología de la Facultad de Medicina Veterinaria de la Universidad Nacional Mayor de San Marcos durante el periodo 2000-2006.

- Los antibióticos con mayores índices de sensibilidad bacteriana frente al $S$. intermedius fueron las cefalexinas.

\section{Literatura Citada}

\section{Bauer A, Kirby W, Sherris J, Turck}

M. 1966. Antibiotic susceptibility testing by standardized single disk method. Am J Clin Pathol 45: 493-496.

2. Cavalcanti S, Coutinho S. 2005. Identificação e perfil de sensibilidade antibacteriana de Staphylococcus spp. isolados da pele de cães sadios e com piodermite. Clín Vet 58: 60-66. 
3. De Boer DJ. 1997a. Recurrent canina pyoderma: predisposing factors and diagnostic approach. In: Proc. $14^{\text {th }}$ Annual Congress of the European Society of Veterinary Dermatology. Pisa, Italy. p 9-12.

4. De Boer DJ. 1997b. Tratamiento de la piodermia crónica y recurrente en el perro. En: Bonagura J, Kirk, RW (eds). Terapéutica veterinaria de pequeños animales. México DF: McGraw-Hill Interamericana. p 659-666.

5. Ganière J, Medaille C, Mangion $C$. 2002. Antimicrobial drug susceptibility of Staphylococcus intermedius clinical isolates from canine pyoderma. $\mathrm{J}$ Vet Med 52: 25-31.

6. Ihrke PJ. 2000. Infecciones integumentarias - infecciones bacterianas de la piel. En: G. Greene (ed). Enfermedades infecciosas en perros y gatos. Cap. 85. México DF: McGraw-Hill Interamericana. p 595-602.

7. Joklik W, Willett H, Wilfert C. 1997. Microbiología Zinsser. 20 ed. Buenos Aires: Médica Panamericana. 1696 p.

8. Kwochka K. 2000. Management of recurrent pyoderma. En: XVII Congreso Panamericano de Ciencias Veterinarias. Panamá. p 146-148.

9. Lima L, Cysneiros A, Siquiera Jr, Barreto H. 2001. Caracterização de linhagens de Staphylococcus resistentes a drogas isoladas de infecções superficiais de cães na cidade de Natal. En: XXI Congreso Brasileiro de Microbiologia. Río de Janeiro, Brasil.p 198.

10. Lorenzana LC, Gómez MC. 2005. Piodermia canina. [Internet], [10 diciembre 2006]. Disponible en: http:// www.webveterinaria.com/virbac/news3/ pioderma.pdf

11. Malik S, Peng H, Barton M. 2005. A review: antibiotic resistence in staphylococci associated with cats and dogs. J Appl Microbiol 99: 1283-1293.

12. Mason I. 1996. Canine pyoderma. In: Proc. Clinical Programme $3^{\text {rd }}$ World Congress of Veterinary Dermatology. Edimburgh, Scotland. p 29-32.
13. Medleau L, Long R, Brown J, Miller W. 1986. Frequency and antimicrobial susceptibility of Staphylococcus species isolated from canine pyodermas. Am J Vet Res 47: 229-231.

14. [NCCLS] National Committee for Clinical Laboratory Standards. 1997. Approved standard M2-A6. Performance standards for antimicrobial disk susceptibility test. $6^{\text {th }}$ ed. Wayne, USA: NCCLS.

15. Noli C, Houwers D, Willemse T. 1995. Study of the resistance patterns of Staphylococcus spp. isolated from dogs with pyoderma. In: Proc. $12^{\text {th }}$ Annual Congress of the European Society of Veterinary Dermatology. Barcelona, Spain.

16. Pianta C, de Oliveira S, Bello L, Telles $A$, da Silva $V$. 2006. Pioderma estafilococócico: identificação das espécies e sensibilidade aos antimicrobianos. Rev Cienc Agrovet 5: 60-63.

17. Rème C, Médaille C. 2003. Antimicrobial susceptibility amongst canine pyoderma isolates of Staphylococcus intermedius in France between 1997 and 2001. [Internet], [20 agosto 2006]. Available in: http://www.vetcontact.com/presentations/ show.php?act=show\&vid $=370 \&$ langselect $=$ en\&lang $=$ es \&ucnt $=56 \&$ pflag $=1 \&$ fglyt

18. Šeol B. 2005. Comparative in vitro activities of enrofloxacin, ciprofloxacin and marbofloxacin against Staphylococcus intermedius isolated from dogs. Vet Arhiv 75: 189-194.

19. Simoons-Smit A, Salvelkoul P, Stoof J, Starink T, Vandenbroucke-Grauls $\boldsymbol{C}$. 2000. Transmission of Staphylococcus aureus between humans and domestic animals in a household. Eur J Clin Microbiol 19: 150-152.

20. Sumano H, Ocampo L. 1997. Farmacología veterinaria. $2^{\mathrm{a}}$ ed. México DF: McGraw-Hill Interamericana. 685 p.

21. Swango L, Bankemper K, Kong L. 1992. Infecciones por bacterias, rickettsias, protozoarios y otros. En: Ettinger S (ed). Tratado de medicina interna veterinaria, enfermedades del perro y el gato. Cap. 46. Buenos Aires: Ed. Inter-médica. p 293-294. 